\title{
And the Story Evolves: The Development of Personal Narratives and Narrative Identity
}

\author{
Kate C. McLean \\ Western Washington University
}

Correspondence can be addressed to Kate McLean at: Western Washington University, 516 High

Street, MS 9172, Bellingham, WA 98225; Kate.McLean@wwu.edu

Acknowledgements. I thank Jennifer Lilgendahl for comments on an earlier version of this manuscript.

McLean, K. C. (2017). And the Story Evolves: The Development of Personal Narratives and Narrative Identity (pp. 325 - 338). In J. Specht (Ed.), Personality Development Across the Lifespan. Elsevier. 


\begin{abstract}
The present chapter reviews research on the development of narrative identity in childhood, adolescence, and across adulthood. Rooted in McAdams' (2013) three-level framework, narrative identity is defined as a level of personality that is more idiographic, dynamic, and contextual than traits and characteristic adaptations. Beginning in early childhood children begin to learn how to tell stories in past-event conversations with their parents. The manner in which parents talk with their children predicts those children's own narrative representations of themselves into adolescence. Across adolescence a depth in autobiographical reasoning grows, which allows individuals to begin to construct a life story, or narrative identity. Across adulthood change and stability in stories is discussed, concluding with speculations on links between developmental and personality approaches to narrative, as well as a consideration of personality integration in adulthood.
\end{abstract}

Key Words: narrative identity, narrative development, personality development, parent-child reminiscence 


\section{And the Story Evolves: The Development of Personal Narratives and Narrative Identity}

In the early 1990s Dan McAdams (e.g., 1993) proposed that personality had more to it than traits. McAdams was not the first person to say this; the history of personality psychology is full of approaches beyond traits (e.g., Carlson, 1971). However, this was the first attempt to describe a personality psychology that included not only traits, but also other personality constructs in one integrative model (see also McAdams \& Pals, 2006). As part of this integrative model, the third level of personality was introduced (see also McAdams, 1988): the life story, now often called narrative identity (McAdams \& McLean, 2013; Singer, 2004; see also Murray, 1938; Tompkins, 1979). Since McAdams' initial writings the study of narrative identity has taken off and is now a robust field with much to offer scholars interested in personality development.

\section{Personality Development at Three Levels}

McAdams' three levels include traits, characteristic adaptations, and the life story. More recently, McAdams (2015) has argued that these three levels can be understood as increasingly sophisticated layers of development, subsumed under the metaphors of actor, motivated agent, and author. This developmental progression encompasses a 'whole person' perspective as it takes into account multiple aspects of persons, and includes the context of development in these layers. Further, each layer represents a unique aspect of personality; none is a derivative of the other (but see DeYoung, 2015).

Actor. The actor-self emerges early in the form of temperament, unfolding over time to eventually represent adult personality traits. McAdams discusses the earliest form of the actor self as represented by emotional communication, such as social smiles, and increasing emotional expression (e.g., distress moving from sadness, anger, or fear) (Izard, Fantauzzo, Castle, Haynes, 
Rayias, \& Putnam, 1995). These early expressions of emotions foreshadow some of the more emotion-based traits, such as extraversion and neuroticism (Shiner \& DeYoung, 2013). Still later, we see the emergence of self-regulation, a component of the actor self that relates to conscientiousness. Thus, very early in development individual differences in behavior and emotional expression appear and portend later trait development, showing the enduring, relatively stable, and relatively biologically-based layer of personality (Asendorph, Denisson, \& van Aken, 2008; Caspi, Harrington, Milne, Amell, Theodore, \& Moffitt, 2003; McCrae \& Costa, 2008).

Agent. The motivated agent emerges towards the end of early childhood when children become more intentional, and more independently goal-directed as they begin to experience a feeling of self-efficacy with their growing skills, which coincides with the time that they also begin school in contemporary industrialized societies (McAdams, 2015). McAdams pays particular attention to motives in the articulation of level two of personality. Motivations are a component of personality that has been dominated by measures of unconscious needs (McClelland, 1961; Murray, 1938), such as agency and communion (see McAdams, 1988). Though there is an evolutionary adaptation to needs (e.g., for functioning hierarchies; Hogan, 1982), as well as for well-being (e.g., Deci \& Ryan, 2012), contemporary research is rather silent on whether these motives are learned or hardwired, though early theorists fell on the side of learning (McClelland, 1961; Murray, 1938). Regardless, what occurs during middle childhood is the development of the layer of personality that reveals differences in human needs, needs that locate the self in an interpersonal web of society, making this layer more contextualized and responsive to cultural and environmental presses (see also DeYoung, 2015). 
Author. The author-self emerges in adolescence with the skills for abstract reasoning and the personal and social demand to develop an identity (Habermas \& Reese, 2015; McAdams, 2015; McAdams \& McLean, 2013). The life story, or narrative identity, is a story of how the person came to be the person she currently is: how did I get here, who am I, and where am I going? There are many experiences in a life, but only some are remembered, and only some of those are particularly salient and connected to self-understanding. Beginning in adolescence it is the job of the individual to select the events that can be strung together to create a narrative arc of one's life, and in so doing, constructing that story brings a sense of coherence, integration, and purpose to the individual (McAdams, 1993).

Compared to the first two levels, narrative identity is more contextual and more idiographic. Further, this story (and the episodes that comprise it) is a subjective construction built by the individual, in interaction with his her proximal and distal surrounds (Nelson \& Fivush, 2004; McAdams, 2006; McLean, 2015; McLean \& Syed, 2015; Pasupathi, 2001; Thorne, 2000). And this story is not static. It evolves with new experiences and new ways of understanding the self (Josseleson, 2009). Thus, though there is some stability to narrative identity, discussed below, narrative identity is not as stable as traits, nor is there extant evidence that it is as biologically rooted as traits. Indeed, it is largely a level of personality that is defined by the dynamics of individual development and contextual interchange.

Before diving into the research on development, I offer a brief note on methodology. First, there are a wide variety of ways of collecting narrative data. The great majority (particularly the kinds that are reviewed here) come from narratives communicated in naturalistic conversations, via semi-structured interviews, or via written form. Most often researchers focus on the coding of specific autobiographical memories within those three types of narrative 
elicitation. Second, although all narrative data are originally solicited in qualitative form, there there are also a large variety of approaches to analyzing those narratives, from classically qualitative work such as case studies, to mixed methods approaches that combine quantitative and qualitative data, to purely quantitative work in which relevant aspects or dimensions of narrative are assigned numbers for statistical analysis. In terms of how narratives are assessed, I will not provide an exhaustive list of the dimensions that are coded. Indeed, there are a wide variety of potential ways to code narratives, and there is no finite consensus on all of the ways of doing so (further new codes and assessments emerge with new research questions, new samples, or different kinds of data). However, there is some degree of consensus concerning dimensions, which are most often used in quantitative studies, and which are housed under the umbrellas of motivational themes (e.g., agency and communion), affective themes (e.g., positivity or negativity of the narrative), themes of integrative meaning (e.g., interpretive evaluation), and structural elements (e.g., coherence, complexity) (see Adler et al., in press, for an overview of these categories, as well as some further discussion about assessment; see also Syed, in press). I turn now to the research on the development of narrative identity.

\section{The Development of Narrative Identity: Childhood through Adolescence}

Although McAdams' (2015) recent work has provided a developmental framework for the three levels, the thrust of the theory is about understanding adult personality integration. I find this to be an important point because, at the same time that McAdams was developing his model, developmental psychologists were developing a theory to explain the early emergence of the autobiographical self, scholarship rooted in both cognitive theories of memory, as well as socio-cultural theories of development (Nelson \& Fivush, 2004). Some thirty years later, these two fields are beginning to merge (see McAdams \& Zapata-Ziel, 2015; McLean, 2008; Reese, 
Chen, Jack, \& Hayne, 2010; Thorne, 2000), revealing a full palate of scholarship in the development of narrative identity, as well as its consequences as an individual difference.

The parallel work done by developmental psychologists has focused not on personality, but on the development of the early skills that turn out to be quite important in constructing a life story in adolescence and emerging adulthood. This research is rooted in a Vygotskian (1978) approach, in which participation in culturally valued activities is the engine of development (see also Rogoff, 2003). The activity of interest here are the past-event conversations that parents have with their children as soon as they are verbally able (see Fivush, Haden, \& Reese, 2006, for a review). In these daily, natural conversations about a trip to the zoo, to a grandparent's house, or what happened at day care, parents scaffold the development of early narration skills (e.g., the format and content of culturally valued stories), as well as the value of telling stories for social connection and to define and understand the self through time (e.g., Fivush, Bohanek, \& Duke, 2008).

Although individual differences from a personality perspective have not been the focus of this work (cf., Laible, Murphy, \& Augustine, 2013), variability in parental reminiscing is evident and meaningful. Researchers have identified variability in how parents talk to their children about these past events (Fivush \& Fromhoff, 1988), variability that predicts different kinds of narrative patterns in children's own narratives in cross-sectional, longitudinal, and experimental designs (see Fivush et al., 2006 for a review). In short, parents who elaborate more with their children in these conversations, have children with more elaborative narratives themselves. Intriguingly, parent-child reminiscing is also a predictor of the volume of memories that adolescents recall from early childhood (Reese, Jack, \& White, 2010), suggesting that the more parents engage with their children in these reminiscing contexts the more material adolescents 
have to work with once the narrative identity task is engaged. Further, parents may be more important than the children themselves in some cases. Reese, Chen et al. (2010) found that parents' references to emotions in early childhood conversations predicted the ways in which adolescents discussed their own emotions at independent assessments years later. In contrast, the adolescents' own references to their own emotions in early childhood did not predict how they discussed past events in adolescence.

Elaborative narratives are particularly important for identity development because it is in the interpretive work where identity is constructed (Habermas, \& Köber, 2015; McLean \& Pratt, 2006; Pasupathi, Brubaker, \& Mansour, 2007; Pasupathi \& Wainryb, 2010). Indeed, there are marked increases in measures of narrative interpretation, or autobiographical reasoning (Habermas \& Bluck, 2000), in adolescence (Habermas \& de Silveira, 2008; McLean, Breen, \& Fournier, 2008; Pasupathi \& Wainryb, 2010), the stage when the developmental task turns towards the development of identity (Erikson, 1968). Autobiographical reasoning can take many forms, but at its heart is the narration of stories that elaborate on connections between past events and current self-understanding.

However, it does not seem that it is simply the style that parents use in these conversations - elaborative or not - that is important. It is the style used when discussing specific kinds of events. In particular, conversational elaboration in the context of negative past events, predicts children's self-esteem and self-concept during early childhood (Bird \& Reese, 2006). Mothers' references to their children's negative emotions in early childhood was especially predictive of those same children's independent narration of their own emotional experiences in adolescence (Reese, Chen et al. 2010). Thus, there is something about the engagement of particularly challenging events that seems to stick as children begin the work of 
developing their narrative identities. This finding is echoed in research on adult narrative identity, where we see the importance of managing negative events for identity and well-being (e.g., Pals, 2006), work which is discussed below.

Finally, it is in later adolescence and emerging adulthood that narrative characteristics become more clearly connected to other markers of personality. For example, in a cross-sectional study Reese and colleagues (Reese et al., 2014) found significant relations between traits and narrative characteristics for middle and late adolescents, but not for early adolescents, suggesting that it may take some time for these aspects of personality to become integrated. Emerging adulthood is also the time when narrative characteristics become clearly, and consistently, related to aspects of well-being (see Adler, Lodi-Smith, Phillipe, \& Houle, 2015 for a review; see also McAdams \& Cox, 2010), In sum, beginning at some point between adolescence and emerging adulthood, it appears that the life story begins to emerge, and begins to represent a more stable individual difference in personality.

\section{Narrative Identity in Adulthood}

We are now at the developmental point where the literature meets its division between the developmentalists - who have documented the change and maturation that occurs in narrative skill across the childhood and adolescent years, as well as potential mechanisms of that change and the personality psychologists who have documented the nature of individual differences in narrative identity, particularly as they relate to well-being and psychological functioning, often above and beyond traits (see Adler et al., 2015 for a review). What we lack currently is a clear understanding of how these developments in childhood and adolescence connect to adult development. I will speculate on the connections between these parts of the lifespan in closing, but for now I turn to the research on narrative identity in adulthood, and where and why we see 
development in this level of personality, with particular attention to the development of stories themselves.

\section{The Evolution of the Story: Stability or Change?}

There at least three ways to think about change over time in narratives: change in 'style,' change in interpretation, and change in content. I address each of these, but I note at the outset that existing empirical evidence is relatively scant. However, I spend some time exploring this question of change and stability because I think it may be a new frontier in research on narrative identity. Thus, I also speculate on whether and why we should see changes in stories.

Changes in Style, Regardless of Event Narrated. McAdams (McAdams, Bauer, Sakeda, Anyidoho, Machado, Magrino-Failla, White, \& Pals, 2006) and Thorne (Thorne, Cutting \& Skaw, 1998) both conducted longitudinal studies of the stability of coded qualities of stories over time in college student samples. McAdams' study was over a 3-month and 3-year period, and Thorne's study was over a 6-month period. In McAdams' study rank-order stability coefficients were strongest from $1-3$ months (not surprisingly), but were notable nonetheless, ranging from .35 over 3 years for personal growth to .53 for narrative complexity. Emotional tone was also rather stable (.43), as were themes of agency (.45). Thorne et al. also found moderate stability in themes and motivations over the 6-month time period.

Bbeyond these markers of stability in the style of telling stories, there was also expected change in stories over time at the mean level. McAdams et al. found that indices of personal growth, complexity, and positive valence increased over time, likely reflecting a growing maturity and comfort in self (see also Habermas \& Berger, 2011). It is possible that we would continue to see such change across young adulthood, which may asymptote in mid-life as identity becomes more consolidated and integrated (Diehl, Hastings, \& Stanton, 2001), and as 
other aspects of personality mature (Roberts, Walton, \& Viechtbauer, 2006; Soto, John, Gosling, \& Potter 2011) (see also Pasupathi \& Mansour, 2008). Thus, there is meaningful cross-time stability to the ways that individuals narrate their experiences but, perhaps particularly during the period of intense development in emerging adulthood, there is also reasonable change and development, reflecting the dynamism of this particular level of personality.

Changes in Interpretation of the Same Events. When examining the same events over time there is also evidence for change. The best example of this comes from a single case study of the assessment of one woman's life story at 4 time points from $21-55$ years of age (Josselson, 2009). In this analysis, Josselson showed how the same event is told and reinterpreted in relation to current life tasks and experiences. For example, the event of a relationship in college is interpreted as a romantic story about individuating from family in her 20's, as the negative contrast to her present husband in her 30's, is untold in her 40's, and in her 50 's the story returns to a more positive valence and is told as a reminder of her passionate and sexual self. Thus, this same event becomes storied in different ways over time as this woman herself changes over time. In some ways it serves a different function, allowing her to reinterpret the past to serve her needs in the present.

In thinking about how a particularly story should change, Habermas and Berger (2011) posit that at first an event may be saturated with detail and emotion as it is being processed. As it is processed and integrated into one's larger story (or let go), the details lessen as the event becomes less emotional and resolved (see also Fivush, Sales, \& Bohanek, 2008; Pals, 2006; Pennebaker \& Beall, 1986). Indeed, Habermas and Berger (2011) found that over a three-month period, repeated narratives of emotional events became less emotionally pressing, more condensed, storied from a more distant perspective, and narrated with higher rates of closure. 
Together these two studies show normative changes in how the same event is narrated across time, as well as how life stories evolve with developmental context and shifting self-perceptions.

Changes in Content - New Stories. The studies on changes in interpretation raise the question of how much content actually remains in our narrative identities? Existing data suggest not much, at least for emerging adults. McAdams et al. (2006) found that about $25 \%$ of stories were repeated from $1-3$ months, and about $13 \%$ were repeated from $1-3$ years. In Thorne et al.'s (1998) study, only $14 \%$ of the stories constituted 'twice-told tales' over a 6-month period. In Thorne's study there were no thematic differences between once-told and twice told stories, though twice-told stories were older than once-told stories, and showed a 'reminiscence bump of density between the ages of 16 - 20 (Rubin, Rahhal, \& Poon, 1998). Thus, across both of these studies repeated, specific content was relatively rare. The participants in these studies were of course in a period of relatively dramatic personal change, represented by experiencing many novel and intense events (e.g., Rubin et al., 1998), as well as relatively high trait change (Roberts et al., 2006). Thus, we would expect repeated content to be rarer in this developmental stage. Josselson's study suggests that for mid-life, or maybe even older, adults there may be more stability in content, even if interpretation of that content changes, but this is a question that remains to be tested.

\section{How Stable Should Stories Be in Adulthood?}

Given the inherency of stability in personality trait theories (McCrae \& Costa, 2008), it makes sense to examine whether there is stability in story characteristics. Indeed, the data to answer the stability question (McAdams et al., 2006; Thorne et al., 1998) were collected and analyzed from a 'traditional' personality lens, in which cross-time stability is a focal piece of evidence for the existence of personality (e.g., Block, 1981; Funder, 1983). However, from a 
different lens it is also the case that this framework about trait personality may not apply to the narrative level of personality.

Indeed, these are markedly different aspects of personality. Traits center on individual differences in cognition, behavior, and affect. The life story is about identity, and identity is not something that sits on the shelf once developed; it is sensitive to context, to time, to new experiences, to new ways of understanding the self and the world (Erikson, 1968). In fact, narrative identity has not necessarily been defined by its stability; it has been defined as an ongoing 'project.' Thus, we expect some aspects of narrative to change over time, such as the content of stories as new experiences arise, the understanding of one's past as new insights develop, and the interpretation of stories with growth in maturity or wisdom.

Therefore, it makes sense that in McAdams et al.'s longitudinal study they found stability in personal growth, but less so than other aspects of narrative. We would expect increases on personal growth across the college years - that makes sense from the perspective of exploring and integrating an identity (see also Carlsson, Wängqvist, \& Frisén, 2015). Conversely, certain aspects of events are more likely to stay the same, such as their temporal ordering (e.g., Schiff, 2005), or perhaps the coherence of a story. This is a reminder that given the diversity of ways that one can analyze narratives, clarity about what narrative characteristics one is investigating is critical (e.g., McLean, Pasupathi, Fivush, Greenhoot, \& Wainryb, 2015). That is, changes in the emotional hue, coherence, or interpretive processes may each show differential patterns of stability and change.

Finally, in thinking about why some stories do retain some markers of stability, Thorne and Nam (2009) suggest that telling same story over time may "enhance personality continuity." Indeed, when we hold on to certain stories the narrative arc may solidify, and may integrate with 
other aspects of personality for greater stability over time. Further, just as with trait development, 'evocative forces' may also work to maintain story stability: others may ask us to recount the favorite tale, or we may be drawn to situations that evoke the humorous or the dark tales.

However, Thorne and Nam also suggest that repeated storytelling may also constrain personality development. The longer the story has been around, the harder it may be to change it. Indeed, I have recently written about the drive to maintain stability in narrative identity that is both internal and external (McLean, 2015; see also McLean \& Syed, 2015). The importance of predictability to reduce uncertainty and anxiety is a part of the human condition, a motive that drives one to maintain homeostasis. This drive can be beneficial, if the story still fits. But it can be harmful if the story no longer fits, or if it constrains meaningful personal growth and development. Further, this is not only an internal drive. Others, too, are also invested in this stability. We want to predict how others will act, and we want to think we know who they are. Others may constrain the evolution of personal stories to maintain their own homeostasis, perhaps especially close others, such as the family (McLean, 2015).

This need to maintain homeostasis may be particularly challenged when external events demand a rewriting, or a new story all together. For example, a divorce may change the story of one's relationship arc in rather substantive ways. Just as obtaining a job may demand greater conscientiousness (e.g., Roberts, 1997), some experiences may demand a revision of our identities.

\section{How the Story Evolves in Relation to other Levels of Personality and Earlier Developments}

Clearly identity narratives do not arise out of thin air. They are deeply embedded in earlier social-cultural practices, such as parental reminiscence, as well as earlier developing components of personality. That is, this level of personality requires a skill that develops, and is 
likely shaped by other parts of ourselves that precede the development of narrative identity.

In terms of connections with traits, Lodi-Smith, Geise, Robins, and Roberts (2009) found that traits at the beginning of college predicted specific characteristics of narratives at the end of college. In a mid-life sample, Pals (2006) found that exploratory processing at age 52 was rooted in the trait of coping openness at age 21 . Thus, we would expect that traits may shape stories, from their emotional tone, with those high on neuroticism telling more negative stories, to their structure, with those high on openness telling more complex stories (McAdams et al., 2004), to the manner of telling them, with those high on extraversion engaging in more frequent narration (e.g., McLean \& Pasupathi, 2006).

However, storytelling is a dynamic process and stories have the power to changes selves as well (see McLean, Pasupathi, \& Pals, 2007). For example, Adler (2012) documented that, over 12-weeks, changes in narratives preceded changes in mental health (see also Cox \& McAdams, 2014). In Pals' (2006) longitudinal study narrative processing served as a mediator between early trait coping openness and later maturity at age 61. Although the focus of this chapter has been on stability and change within stories themselves, these studies also show that stories can also serve as a mechanism for change within the person. Thus, as the story evolves so too does the person.

In terms of the social-cultural context, Reese's longitudinal study (Reese et al., 2010) is the first to document connections between the early parent-child reminiscing context and narrative identity in adulthood. Here we see that parental reminiscing practices are uniquely important in predicting how their children narrate their own lives independently in adolescence.

Connecting these two areas of research it appears that early reminiscing contexts interact with personality, in both mothers and children. For example, children who are temperamentally 
more active and less sociable experience more repetition in past-event conversations (Lewis, 1999), and children with more effortful control have mothers who are more elaborative (Laible, 2004; Laible et al., 2013). This suggests that child temperament is an evocative force that can draw out varying styles of reminiscence. Maternal personality may also matter. In one of the few studies on the matter, Laible et al. (2013) found that mothers higher on openness to experience discussed causes of and potential coping strategies for negative emotions more than those lower on openness. Further, genetic similarity between parents and children may underlie some of these effects, as when we see the association between elaboration on the parent's side, and then subsequently on the child's side later in development, perhaps reflecting a passive geneenvironment correlation.

\section{Conclusion}

As was articulated in discussing the research on narrative there are many components to a story. That is, there are many characteristics to examine, such as emotional tone, complexity, and interpretive content, all with different meaning for change, stability, and psychological functioning. One way to organize the many components for analysis is to think about integration (Syed \& Mitchell, 2015), such that what may in fact be developing across adulthood is an integrated identity.

Syed and McLean (in press) recently argued that there are three types of identity integration - contextual, temporal, and ego integration, or the integration of both time and context - all of which can be accomplished via narrative. Contextual integration is the bringing together of multiple aspects of self, such as various content domains of identity (e.g., politics, religion, and family), as well as other aspects of individuals such as ethnic or gender identity. Temporal integration has been my main focus for this chapter, and addresses making sense of the 
self across time. The final form of integration is making sense of the self across context and time. Syed and McLean (in press) argued that ego integration most closely represents McAdams' (2013) idea of the integrated life story (see also Lilgendahl, 2015). There is far less research on this type of integration; indeed, it is hard to hold this many variables in mind (see Azmitia, Syed, and Radmacher, 2008).

To add to these layers of complexity, it may also be that an integration of multiple aspects of personality is also developing in adulthood. There has been little work as of yet on how to integrate McAdams' three levels (see DeYoung, 2015; Lilgendahl, 2015; Syed \& McLean, in preparation). There has been a good deal of work examining the incremental validity of various iterations of the three levels (e.g., Adler et al., 2015), as well as interactions between various levels in predicting a valued outcome (e.g., Lilgendahl \& McAdams, 2011). But how do the three levels work together? For example, what does it mean that traits and narratives are not clearly connected until mid to late adolescence (Reese et al., 2014)? How do we conceptualize these levels in interaction? This work on personality integration may be the focal point of narrative development in adulthood.

In closing, I note that there are really two questions threaded throughout this chapter. The first is about the construction of a life story, a story that while rooted in earlier narrative developments, did not exist before. The second is about the evolution of that story once constructed as the person him or her self is evolving. Given these two issues, at least two clear questions arise from the extant research. What facilitates the construction of that story - clearly reminiscence practices and other aspects of personality are important. What facilitates the evolution of that story? Here we know less, given the paucity of longitudinal work. However, personality traits seem to matter, and changes in that story matter for psychological functioning. 
This is an exciting new frontier for narrative researchers, and I look forward to the evolution of the story. 


\section{References}

Adler, J.M. (2012b). Living into the story: Agency and coherence in a longitudinal study of narrative identity development and mental health over the course of psychotherapy. Journal of Personality and Social Psychology, 102(2), 367-389.

Adler, J.M., Lodi-Smith, J., Phlippe, F.L., \& Houle, I. (2015). The incremental validity of narrative identity in predicting well-being: A review of the field and recommendations for the future. Personality and Social Psychology Review.

Asendorph, J. B., Denisson, J. J., \& van Aken, M. A. (2008). Inhibited and aggressive preschool children at 23 years of age: personality and social transitions into adulthood. Developmental Psychology, 44, 997-1011.

Azmitia, M., Syed, M., \& Radmacher, K. (2008). On the intersection of personal and social identities: Introduction and evidence from a longitudinal study of emerging adults. In M. Azmitia, M. Syed, \& K. Radmacher (Eds.), The intersections of personal and social identities. New Directions for Child and Adolescent Development, 120, 1-16. San Francisco: Jossey-Bass.

Bird, A., \& Reese, E. (2006). Emotional reminiscing and the development of an autobiographical self. Developmental Psychology, 42, 613-626.

Block, J. (1981). Some enduring and consequential structures of personality. In A.I. Rabin, J.

Arnoff, A. M. Barclay, \& R. A. Zucker (Eds.), Further explorations in personality (pp. 27-43). New York: Wiley.

Carlson, R. (1971). Where is the person in personal- ity research? Psychological Bulletin, 75, 203-219. 
Carlsson, J., Wängqvist, M., \& Frisén, A. (2015). Identity development in the late twenties: A never ending story. Developmental psychology, 51(3), 334.

Caspi, A., Harrington, H. L., Milne, B., Amell, J., Theodore, R. F., \& Moffitt, T. E., 2003

Cox, K., \& McAdams, D. P. (2014). Meaning making during high and low point life story episodes predicts emotion regulation two years later: How the past informs the future. Journal of Research in Personality, 50, 66-70.

Deci, E. L., \& Ryan, R. M. (2012). Self-determination theory. In P. A. M. Van Lange, A. W. Kruglanski, \& E. T. Higgins (Eds.), Handbook of theories of social psychology: Vol. 1 (pp. 416437). Thousand Oaks, CA: Sage.

DeYoung, C. G. (2015). Cybernetic big five theory. Journal of Research in Personality, 56, 33 58.

Diehl, M., Hastings, C. T., \& Stanton, J. M. (2001). Self-concept differentiation across the adult life span. Psychology and Aging, 16, 643-654.

Erikson, E. (1968). Identity, Youth and Crisis. New York, NY: W W Norton \& Co.

Fivush, R., Bohanek, J.G., \& Duke, M. (2008). The intergenerational self: Subjective perspective and family history. In F. Sani (Ed.). Individual and Collective SelfContinuity. Mahwah, NJ: Erlbaum.

Fivush, R., \& Fromhoff, F. (1988). Style and structure in mother-child conversations about the past. Discourse Processes, 11, 337-355.

Fivush, R., Haden, C. A., \& Reese, E. (2006). Elaborating on elaborations: Role of maternal reminiscing style in cognitive and socioemotional development. Child Development, 77, 1568-1588.

Fivush, R., Sales, J. M., \& Bohanek, J. G. (2008). Meaning making in mothers' and children's 
narratives of emotional events. Memory, 16(6), 579-594.

Funder, D. C. (1983). Three Issues in Predicting More of the People: A Reply to Mischel and Peake. Psychological Review, 90, 283-290.

Habermas, T., \& Berger, N. (2011). Retelling everyday emotional events: Condensation, distancing, and closure. Memory and Emotion, 25, 206-291.

Habermas, T., \& Köber, C. (2015). Autobiographical reasoning in life narratives buffers the effect of biographical disruptions on the sense of self-continuity. Memory, 23, 564-574.

Habermas, T. \& Reese, E. (2015). Getting a life takes time: The development of the life story in adolescence, its precursoes and consequences. Human Development, 58, 172-201.

Hogan, R. (1982). A socioanalytic theory of personality. In M. Paige (Ed.), Nebraska symposium on motivation (Vol. 29, pp. 55-89). Lincoln: University of Nebraska Press.

Izard, C. E., Fantauzzo, C. A., Castle, J. M., Haynes, O. M., Rayias, M. F., \& Putnam, P. H. (1995). The ontogeny and significance of infants' facial expressions in the first nine months. Developmental Psychology, 31, 997 - 1013.

Josselson, R. (2009). The present of the past: Dialogues with memory over time. Journal of Personality, 77, 647-668.

Laible, D. (2004). Mother-chold discourse in two contexts: Factors that predict differences in the quality and emotional content of the discourse and consequences of those differences for socioemotional development. Developmental Psychology, 40, 979-992.

Laible, D. Murphy, T. P. \& Augustine, M. (2013). Predicting the quality of mother-child reminiscing surrounding negative emotional events at 42 and 48 months old. Journal of Cognition and Development, 14, 270-291.

Lewis, K. (1999). Maternal style in reminiscing: Relations to child individual differences. 
Cognitive Development, 14, 381-399.

Lilgendahl, J. P. (2015). The dynamic role of identity processes in personality development: Theories, patterns, and new directions. In K. C. McLean \& M. Syed (Eds.), The Oxford handbook of identity development. New York: Oxford University Press.

Lilgendahl, J. P., \& McAdams, D. P. (2011). Constructing stories of self-growth: How individual differences in patterns of autobiographical reasoning relate to well-being in midlife. Journal of Personality, 79, 391-428.

Lodi-Smith, J., Geise, A.C., Roberts, B.W., \& Robins, R.W. (2009). Narrating personality change. Journal of Personality and Social Psychology, 96, 679-689.

McAdams, D. P. (1988). Power, intimacy, and the life story: Personological inquiries into identity. New York: Guilford.

McAdams, D. P. (1993). The stories we live by: Personal myths and the making of the self. New York, NY: Guilford Press.

McAdams, D. P. (2006). The redemptive self: Stories Americans live by. New York: Oxford University Press.

McAdams, D. P. (2015). The art and science of personality development. New York: Guilford.

McAdams, D. P., Bauer, J. J., Sakaeda, A., Anyidoho, N. A., Machado, M., Magrino, K., White, \& Pals, J. L. (2006). Continuity and change in the life story: A longitudinal study of autobiographical memories in emerging adulthood. Journal of Personality, 74, 13711400.

McAdams, D. P., \& Cox, K. S. (2010). Self and identity across the life span. In R. Lerner, A. Freund, \& M. Lamb (Eds.), Handbook of life span development (Vol. 2, pp. 158-207). New York, NY: Wiley. 
McAdams, D. P., \& McLean, K. C. (2013). Narrative Identity. Current Directions in Psychological Science, 22, 233-238.

McAdams, D. P., \& Pals, J. L. (2006). A new Big Five: Fundamental principles for an integrative science of personality. American Psychologist, 61, 204-217.

McAdams, D.P., \& Zapata-Gietl, C. (2015). Three strands of identity development across the human life course: Reading Erik Erikson in full. In K.C. McLean and M. Syed (Eds.), Oxford handbook of identity development (pp. 81-94). New York, NY: Oxford University Press.

McClelland, D. C. (1961). The achieving society. New York, NY: Van Nostrand.

McCrae, R. R., \& Costa, P. T. Jr., (2008). The five factor theory of personality. In O. P. John, R. W. Robins, \& L. A. Pervin (Eds.), Handbook of personality: Theory and research (pp. 159-181). New York: Guilford Press.

McLean, K. C. (2008). The emergence of narrative identity. Social and Personality Compass, 2, $1-18$.

McLean, K. C. (2015). The Co-authored Self: Family Stories and the Construction of Personal Identity. New York: Oxford University Press.

McLean, K. C., \& Pasupathi, M. (2006). Collaborative narration of the past and extraversion. Journal of Research in Personality, 40, 1219-1231.

McLean, K. C., Pasupathi, M., \& Pals. J. L. (2007). Selves creating stories creating selves: A process model of narrative self development in adolescence and adulthood. Personality and Social Psychology Review, 11, 262-278.

McLean, K. C., \& Pratt, M. W. (2006). Life's little (and big) lessons: Identity statuses and 
meaning-making in the turning point narratives of emerging adults, Developmental Psychology, 42, 714-722.

McLean, K. C. \& Syed, M. (2015). A Narrative Approach to Psychology: Bridging the Personal and the Cultural with the Concept of Master Narratives. Manuscript submitted for publication.

Murray, H. A. (1938). Explorations in personality. New York: Oxford University Press.

Nelson, K., \& Fivush, R. (2004). The Emergence of Auto- biographical Memory: A Social Cultural Developmental Theory. Psychological Review, 111, 486 - 511.

Pals, J. L. (2006). Narrative identity processing of difficult life experiences: Pathways of personality development and positive self-transformation in adulthood. Journal of Personality, 74, 1079-1110.

Pasupathi, M. (2001). The social construction of the personal past and its implications for adult development. Psychological Bulletin, 127, 651-672.

McLean, K. C., Pasupathi, M., Fivush, R., Greenhoot, A. G., \& Wainryb, C. (2015). Does within person variability in narration matter and for what? Manuscript submitted for publication.

Pasupathi, M., \& Mansour, E. (2006). Adult age differences in autobiographical reasoning in narratives. Developmental Psychology, 42, 798-808.

Pasupathi, M., Brubaker, J., \& Mansour, E. (2007). Developing a life story: Constructing relations between self and experience in autobiographical narratives. Human Development, 50, 85-110. 
Pasupathi, M., \& Wainryb, C. (2010). On telling the whole story: Facts and interpretations in autobiographical memory narratives from childhood through midadolescence. Developmental Psychology, 46, 735-746.

Pennebaker, J. W., \& Beall, S. K. (1986). Confronting a traumatic event: Toward an understanding of inhibition and disease. Journal of Abnormal Psychology, 95, 274-281.

Reese, E., Jack, F., \& White, N. (2010). Origins of adolescents' autobiographical memories. Cognitive Development, 25, 352-367.

Reese, E., Chen, Y., Jack, F., \& Hayne, H. (2010). Emerging identities: Narrative and self from early child-hood to early adolescence. In In K. McLean \& M. Pasupathi (Eds.), Narrative development in adolescence (pp. 23-43). New York, NY: Springer.

Roberts, B. W. (1997). Plaster or plasticity: Are work experiences associated with personality change in women? Journal of Personality, 65, 205-232.

Roberts, B. W., Walton, K. E., \& Viechtbauer, W. (2006). Patterns of mean-level change in personality traits across the life course: a meta-analysis of longitudinal studies. Psychological Bulletin, 132, $1-25$.

Rogoff, B. (2003). The cultural nature of human development. New York, NY: Oxford University Press.

Rubin, D.C., Rahhal, T.A., \& Poon, L.W. (1998). Things learned in early adulthood are remembered best. Memory \& Cognition, 26, 3-19.

Shiner, R. L., \& DeYoung, C. G. (2013). The structure of temperament and personality traits: A developmental perspective. In P. D. Zelazo (Ed.), The Oxford handbook of developmental psychology (pp. 113-141). New York: Oxford University Press. 
Singer, J. A. (2004). Narrative identity and meaning-making across the adult span: An introduction. Journal of Personality, 72, 437-459.

Soto, C. J., John, O. P., Gosling, S. D., \& Potter , J. (2011). Age differences in personality traits from 10 to 65: Big Five domains and facets in a large cross-sectional sample. Journal of Personality and Social Psychology, 100, 330-348.

Syed, M. (in press). Theoretical and Methodological Contributions of Narrative Psychology to Ethnic Identity Research. In C. Santos \& A. J. Umaña-Taylor (Eds.). Studying ethnic identity: Methodological advances and considerations for future research. Washington, DC: American Psychological Association.

Syed, M., \& McLean, K. C. (in press). Understanding Identity Integration: Theoretical, Methodological, and Applied Issues. Journal of Adolescence.

Syed, M., \& McLean, K. C. (in preparation). Integrating the Three Levels of Personality: An Empirical Test of some Possible Structures.

Syed, M., \& Mitchell, L. L. (2015). Temporal identity integration as a core developmental process. In R. Scott, \& S. Kosslyn (Eds.). Emerging Trends in the Social and Behavioral Sciences (pp. 1-15). San Francisco, CA: Wiley.

Thorne, A. (2000). Personal memory telling and personality development. Personality and Social Psychology Review, 4, 45-56.

Thorne, A., Cutting, L., \& Skaw, D. (1998). Young adults' relationship memories and the life story: Examples or essential landmarks? Narrative Inquiry, 8, 1-32.

Thorne, A., \& Nam, V. (2009). The storied construction of personality. In P. J. Corr \& G. Matthew (Eds.), The Cambridge handbook of personality (pp. 491-505). Cambridge: Cambridge University Press. 
Tompkins, S. S. (1979). Script theory: Differential magnification of affects. In H. E. \& Ra. A. Dienstbier (Eds.), Nebraska symposium on motivation. Lincoln, NE: University of Nebraska Press.

Vygotsky, L. S. (1978). Mind in society. Cambridge, MA: Harvard University Press. 